\title{
Association of Serum Adiponectin with Serum Insulin and Body mass density (BMD) in postmenopausal Osteoporotic women with and without T2DM
}

\author{
Kadhim K. Ghudhaib ${ }^{1}$, Kismat M. Turki ${ }^{2}$, Sabreen A. Mezel ${ }^{3}$, Gaze T. Alzedi ${ }^{5}$ \\ And Mohammed H. Alossami ${ }^{6}$ \\ ${ }^{I}$ PhD Clinical Biochemistry $\backslash$ College of Sciences for women University of Baghdad. \\ ${ }^{2}$ PhD Clinical Biochemistry $\backslash$ College of Medicine University of Baghdad. \\ ${ }^{3}$ MSC Biochemistry $\backslash$ College of Sciences for women University of Baghdad . \\ ${ }^{4}$ MSC (Rheum\& Med Rehab). \\ ${ }^{5}$ CABM,Fibms (Rheum\& Med Rehab) Collage of Medicine University of Baghdad .
}

\begin{abstract}
Background: Osteoporosis is a systemic disease of the skeleton, characterized by low bone mass and alteration in the micro-architecture of the bone tissue that lead to an increase in brittleness with the ensuing predisposition to bone fracture. Global statistics show that women are more exposed to this disease than men and in particular at menopause. Like osteoporosis, type 2 diabetes mellitus (T2DM) is also greatly prevalent in aging populations, causing substantial morbidity and mortality. Diabetes mellitus affects skeletal system and bone metabolism through multiple pathways and it has been standard as a major risk factor for osteoporosis.

Objective: To evaluate the level of serum ostocalcin, adiponectin, insulin levels of osteoporotic menopausal women with and without T2DM.

Subjects\& Methods: Blood samples were collected from 90 postmenopausal women; 60 women were patients with osteoporosis who have been divided into 2 groups; group A included 30 postmenopausal patients with osteoporosis without T2DM; group B included 30 postmenopausal patients with osteoporosis and T2DM while the third group included 30 apparently healthy postmenopausal women as a control group .

Serum were separated for the estimation of ostocalcin, adiponectin and insulin by an enzyme-linked immunosorbent assay (ELISA) Kits. Insulin resistance (IR) was calculated in term of homeostatic model assessment (HOMA)

Results: Body mass density (BMD) were significantly lower in osteoporotic menopausal women without T2DM than healthy group; while it is significantly higher in osteoporotic menopausal women with T2DM than the healthy group $(p<0.001)$. The levels of osteocalcin and adiponectin were significantly higher in patients of group A compared with control group $(P<0.01)$, and group $B(P<0.001)$. While serum insulin, fasting serum glucose (FSG), insulin resistance (HOMA-IR) were significantly higher in patients of group B comparedwith the controls and group A. There was a significant negative correlation between adiponectin level and insulin in patients of group $A(r=-0.370, p=0.044)$ And a positive significantly correlation between adiponectin level and BMD in patients of group $B(r=0.419, p=0.021)$.
\end{abstract}

\section{Introduction}

Osteoporosis (OP) is a systemic disease characterized by low bone mass and micro architectural corrosion of bone tissue, resultant in an increased risk of fracture and has touched extensive amount (1). According to WHO, 30\% of postmenopausal women and $70 \%$ of women aged over 80 are affected by osteoporosis (2). Mechanism of osteoporosis includes disorder of the weak balance in process of bone formation and bone reabsorption, which results in long term and uninterrupted bone loss (3). Diabetes mellitus affects skeletal system and bone metabolism through multiple pathways and it has been standard as a major risk factor for osteoporosis (4). Like osteoporosis, type 2 diabetes mellitus (T2DM) is also greatly prevalent in aging populations, causing substantial morbidity and mortality. Demographic trends with longer life expectancy and a lifestyle characterized by low physical commotion and high-energy food intake contribute to the increasing incidence of diabetes mellitus and osteoporosis (5).Dual-energy X-ray absorptiometry (DXA) is considered the standard for the diagnosis of osteoporosis. Osteoporosis is diagnosed when the bone mineral density is less than or equal to 2.5 standard deviations below that of a young adult reference population. This is translated as a Tscore. The World Health Organization has established the following diagnostic guidelines (WHO, 1994) (6):

- $\quad$ T-score -1.0 or greater is "normal"

- $\quad$ T-score between -1.0 and -2.5 is "low bone mass" (or "osteopenia")

- $\quad \mathrm{T}$-score -2.5 or below is osteoporosis 
Circulating levels of adiponectin range between 2 and $30 \mu \mathrm{g} / \mathrm{ml}$ in humans (7). Adiponectin contains 244 amino acid residues and consists of domains signal sequence an N-terminal region without homology to any known proteins, a collagen-like region and a C-terminal globular domain (8). Levels of the hormone are inversely correlated with body fat percentage in adults, while the association in infant and young children is less clear (9).

\section{Subjects and Methods:}

This study was conducted from December 2012 to June 2013, blood samples were collected after 12 hours fasting from a total of 90 postmenopausal women, 60 of them were selected from patients who visited Rheumatology and Rehabilitation Outpatient Clinic in Baghdad Teaching Hospital. Postmenopausal status was defined by the absence of menses for more than one year in a woman 50 year of age and more. Patients were divided into two groups. Group A, included 30 postmenopausal women complaining from osteoporosis without T2DM mean age $(62.33 \pm 8.41$ years), Group B included 30 postmenopausal women complaining from osteoporosis with diabetes mean age $(61.27 \pm 5.67)$ and group $C$ including 30 apparently healthy postmenopausal women mean age of $(60.18 \pm 6.47$ year $)$ as control.

Serum was separated by centrifugation for 10 minutes at $3000 \mathrm{rpm}$ and used to measure the levels of osteocalcin, adiponectin and insulin by enzyme linked immunosorbent assay (ELISA) .

Anthropometrics measurement: weight in kilogram and height in meter were measured for each women and body mass index (BMI) was calculated using the following equation:

$\mathbf{B M I}=\left(\right.$ weight in kilogram / height in meter $\left.^{2}\right)(10)$.

Fat $\%$. Was calculated using the following equation:

Fat $\%=[(1.20 \times \mathrm{BMI})+(0.23 \times \mathrm{Age})-(10.8 \times$ gender $)-5.4](11)$.

Where male gender $=1$, female $=0$.

Insulin resistance (IR) : was determined by a number of different methods. They are including fasting insulin $(\mu \mathrm{U} / \mathrm{ml})$ and glucose $(\mathrm{mmol} / \mathrm{L})$ for calculation the homeostasis model assessment (HOMA) (12).

HOMA-IR $=\left[\frac{\text { fasting blood glucose }(\mathrm{mmol} / \mathrm{L}) \times \text { fasting insulin }(\mu \mathrm{U} / \mathrm{ml})}{22.5}\right]$

\section{Statistical analysis :}

Statistical analyses were performed using SPSS for Windows (version 14). The results were expressed as themean \pm S.D. Student ANOVA was used for statistical analysis, $\mathrm{P} \leq 0.05$ were considered statistically.

\section{Results:}

There were no significant differences $(\mathrm{p}>0.05)$ in the value of BMI, Age and Fat\% for patient groups (A and B) compared with healthy control group (table1). The mean of serum adiponectin level was significantly higher ( $>0.001)$ in patients of group A compared with the control group. The mean of fasting serum insulin in patients of group B was significantly higher $(\mathrm{p}<0.001)$ than that of healthy control and patients of group A as shown in (table 2), also mean value of BMD in groupB were significantly $(\mathrm{p}<0.001)$ higher than that of patient in groups $\mathrm{A}$ and control group(table1)

(Table1): Anthropometrics parameters of the patient and healthy groups.

\begin{tabular}{|c|c|c|c|}
\hline \multirow[b]{2}{*}{ Characteristic } & \multicolumn{2}{|c|}{ Patient groups } & Control group \\
\hline & $\begin{array}{c}\text { group A } \\
{[n=30]}\end{array}$ & $\begin{array}{c}\text { group B } \\
{[n=30]}\end{array}$ & $\begin{array}{l}\text { Group C } \\
{[n=30]}\end{array}$ \\
\hline BMI $\left[\mathrm{Kg} / \mathrm{m}^{2}\right]$ Mean \pm SD & $26.45 \pm 3.05$ & $27.83 \pm 4.25$ & $26.86 \pm 1.98$ \\
\hline Age (y) Mean \pm SD & $62.33 \pm 8.41$ & $61.27 \pm 5.67$ & $60.18 \pm 6.47$ \\
\hline Fat $\%$ Mean \pm SD & $12.001 \pm 3.74$ & $13.90 \pm 4.96$ & $12.99 \pm 2.49$ \\
\hline $\mathrm{BMD}(\mathrm{g} / \mathrm{cm})$ Mean $\pm \mathrm{SD}$ & $0.64 \pm 0.14^{\mathrm{a}, \mathrm{b}}$ & $1.72 \pm 0.093^{\mathrm{a}}$ & $1.09 \pm 0.11$ \\
\hline
\end{tabular}

(Table2): (Mean \pm SD) concentrations of Adiponectin $(\mu \mathrm{g} / \mathrm{ml}), \operatorname{Insulin}(\mu \mathrm{IU} / \mathrm{ml})$ and glucose $[\mathrm{mmol} / \mathrm{L}] \mathrm{in}$ patient and control groups.

\begin{tabular}{|c|c|c|c|}
\hline \multirow[b]{2}{*}{ Characteristic } & \multicolumn{2}{|c|}{ Patient groups } & \multirow{2}{*}{$\begin{array}{c}\text { Control group } \\
\text { Group C } \\
{[n=30]}\end{array}$} \\
\hline & Group A $\quad[n=30]$ & $\begin{array}{l}\text { Group B } \\
{[\mathrm{n}=30]}\end{array}$ & \\
\hline Adiponectin $(\mu \mathrm{g} / \mathrm{ml})$ Mean \pm SD & $11.02 \pm 3.00^{\mathrm{a}, \mathrm{b}}$ & $5.14 \pm 1.55^{\mathrm{a}}$ & $8.63 \pm 1.65$ \\
\hline $\operatorname{Insulin}(\mu \mathrm{U} / \mathrm{ml})$ Mean \pm SD & $9.59 \pm 4.09^{\mathrm{d}}$ & $14.68 \pm 2.75^{\mathrm{a}, \mathrm{b}}$ & $7.13 \pm 0.98$ \\
\hline F.S. G [mmol/l] Mean \pm SD & $5.09 \pm 0.66^{\mathrm{a}} 9.39$ & $9 \pm 1.23^{\mathrm{a}, \mathrm{c}}$ & $4.70 \pm 0.448$ \\
\hline
\end{tabular}


a $\boldsymbol{P}<0.01$ compared with control group.

b $\boldsymbol{P}<0.001$ compared with A.

$c P<0.05$ compared with control group.

d. $P<0.01$ compared with control group

Table (3): Correlation of serum Adiponectin with serum insulin in the three studied groups.

\begin{tabular}{|c|c||c||}
\hline \hline \multirow{2}{*}{} & \multicolumn{2}{|c|}{ Adiponectin } \\
\cline { 2 - 3 } & Correlation- r & P value \\
\hline \hline Group A & $-\mathbf{0 . 3 7 0}$ & $\mathbf{0 . 0 4 4}$ \\
\hline \hline Group B & $-\mathbf{0 . 0 1 9}$ & $\mathbf{0 . 9 2 0}$ \\
\hline \hline Control & $\mathbf{0 . 3 4 9}$ & $\mathbf{0 . 0 5 2}$ \\
\hline
\end{tabular}

*correlation is significant level at 0.05 (2-tiled).

Table (4):Correlation of BMD with Adiponectin in the three studied groups.

\begin{tabular}{|c|c|c|}
\hline \multirow{2}{*}{} & \multicolumn{2}{|c|}{ Adiponectin } \\
\cline { 2 - 3 } & Correlation- $\mathbf{r}$ & P value \\
\hline \hline Group A & $\mathbf{0 . 0 3 2}$ & $\mathbf{0 . 8 6 5}$ \\
\hline \hline Group B & $\mathbf{0 . 4 1 9 *}$ & $\mathbf{0 . 0 2 1}$ \\
\hline Control & $\mathbf{- 0 . 1 0 2}$ & $\mathbf{0 . 5 9 1}$ \\
\hline
\end{tabular}

*correlation is significant level at 0.05 (2-tiled).

\section{Discussion:}

Menopause is one of the most significant risk factors for osteoporosis in women and it is characterized by fast bone loss in newly postmenopausal women. The loss of BMD is accelerate after the cessation of ovarian secretions $(13,14)$. Many studies have shown a link between bone and adiponectin; though, there is no clear understanding of its action on bone. Experimental data are in errand of a positive effect of adiponectin on bone turnover and osteoblastic activation $(15,16)$.

In this study; increasing serum adiponectin levels were associated with a potentially clinically relevant decrease in BMD in osteoporosis. Adiponectin and its receptors have newly been found to be formed by human bone-forming cells, suggesting that adiponectin may be a hormone connecting bone and fat metabolism (17). Further, adiponectin may have harmful effects on bone, as it appear to stimulate the receptor activator of nuclear factor- $\kappa \mathrm{B}$ ligand (RANKL) pathway and inhibit production of the naturally occurring distraction receptor for RANKL, osteoprotegerin (18 ). In T2DM with osteoporosis Adiponectin appear to play an important role in the pathogenesis of type 2 diabetes. Irritated sectional studies have demonstrated that serum concentrations of adiponectin are decreased in type 2 diabetic subjects compared with non diabetic control subjects ( 19,20).

A hypoglycemic effect that is not connected with inspiration of insulin secretion, but rather with increased insulin sensitivity. Experimental studies have shown that the plasma concentration of adiponectin reduces free fatty acids and triglycerides and improve insulin resistance (21). In this study, the (BMD) is significantly higher in lumbar spine of diabetics group. Higher insulin levels in diabetic patients can be an achievable cause of this difference. Higher bone density in diabetic patients without consider BMI, has been shown in previous studies also $(22,23,24)$. An additional reason for high BMD in diabetic patients may be the hyperinsulinism coupled with insulin resistance increases bone mass through effects on bone configuration via IRS-1 and IRS-2 surface receptors on Osteoblasts and by dipping the concentration of sex-hormone binding globulin (SHBG), which leads to increase concentrations of estradiol and testosterone (25).

\section{Conclusions:}

There was a significantly increase in serum Adiponectin level ; in osteoporosis postmenopausal women without T2DM as compared with healthy postmenopausal women and with postmenopausal osteoporosis women with T2DM.Also there was significantly increase in serum Insulin level; in osteoporosis postmenopausal women without T2DM compared with healthy .

\section{References:}

1. Abe, Y.; İshikawa, H. \& Fukao, A.(2008). Higher efficacy of urinary bone resorption marker measurements in assessing response to treatment for osteoporosis in postmenopausal women. J Exp Med. 214(1):51-59.

[2]. Hosoi,T.;Miyao,M.;Inoue,S.;Hoshino,S.;Shiraki,M.;Orimo,H.\&Ouchi,Y.(1999).Association study of parathyroid hormone gene polymorphism and bone mineral density in Japanese postmenopausal woman. Calcify Tissue Int.64 (3):205-208

[3]. G. Salkeld, I. D.; Cameron, R. G.\& et al. (2000).Quality of life related to fear of falling and hip fracture in older women: a time trade off study. Medical Journal.320 (7231): 341-345.

[4]. Leidig-Bruckner,G.\& Zeigler, R. (2001). Diabetes mellitus a risk factor for osteoporosis xp.ClinEndocrinolDiabetes.109(suppl2):S493- S514. 
[5]. Kahn, S.E.; R.L. Hull and K.M. (2006).Utzschneider, Mechanisms linking obesity to insulin resistance and type 2 diabetes. Nature.444 (7121): 840-846

[6]. Oshima, K.;Nampei, A.; Matsuda, M. \&et al.(2005).Adiponectin increases bone mass by suppressing osteoclast and activating osteoblast. BiochemBiophys Res Commun. 331(2):520-526.

[7]. Takahashi,M.;Arita,Y.;Yamagata,K.;Matsukawa,Y.;Okutomi,K.;Horie,M.,\&atl.(2000).Genomic structure and mutations in adipose specific gene, adiponectin.IntJObesRelatMetabDisord.24(7):861-868.

[8]. Waki, H.;Yamauchi, T.; Kamon, J.; Ito, Y. ;Uchida, S.;Kita, S.; Hara, K.;Hada, Y.\&at el.(2003). Impaired multimerization of human adiponectin mutants associated with diabetes: molecular structure and multiyear formation of adiponectin. Journal of Biological Chemistry. 278:40352-40363.

[9]. Ukkola,O. \&Santaniemi, M.(2002).Adiponectin: a link between excess adiposity and associated comorbidities.J. Mol. Med. 80 (11): 696-702.

[10]. Flier, J.\& Maratos-Flier, E. (2005). Obesity. In: Kasper DL. Harrison's principles of Internal Medicine, 16th ed. McGraw-Hill Companies. 64:422-430.

[11]. Deurenberg, P .;Weststrate, JA.; Seidell, J C. (2007). Body mass index as a measure of body fatness: Age- and sex-specific prediction formulas. British Journal of Nutrition.65 (2): 105-114.

[12]. Matthews, DR.;HoskerJP.: Rudenski, AS.; Naylor,BA.;Treacher, D. \&Turner,RC. (1985). Homeostasis model assessment: insulin resistance and beta-cell function from fasting plasma glucose and insulin concentrations in man. Diabetologia. 28(7):412-419 .

[13]. Noedin,BEC. ;Need,AG.; Chatterton, BE.; Horowitz, M.\& Morris, HA.(1990).The relative contributions of age and years since menopause to postmenopausal bone loss. J ClinEndocrinolMetab. 70(1):83-88.

[14]. Hadjidakis,DJ.;Kokkinakis,EP.;Sfakianakis,ME.andRaptis,SA.(2003). Bone density patterns after normal and premature menopause. Maturitas.44(4):279-286.

[15]. Richards, JB.; Burling, K.\&at, al .(2007). Serum adiponectin and bone mineral density in women. J Clin Endocrinal Metab. 92(4):1517-1523.

[16]. Luo,XH.;Guo,LJ.; Yuan, LQ.\&et al. (2005).Adiponectin stimulates human osteoblasts proliferation and differentiation via the MAPK signaling pathway. Experimental Cell Research. $309: 99-109$.

[17]. Luo, XH.; Guo, LJ.; Xie, H.; Yuan, LQ.; Wu, XP.; Zhou, HD.; Liao, EY.(2006).Adiponectin stimulates RANKL and inhibits OPG expression in human osteoblasts through the MAPK signaling pathway. J Bone and Miner Res 21:1648-1656.

[18]. Reid, IR.; Evans, MC.; Cooper, GJ.; Ames, RW.\& Stapleton, J.( 1993). Circulating insulin levels are related to bone density in normal postmenopausal women. Am J Physiol EndocrinolMetab. 265 :E655-E659.

[19]. Hotta,K.;Funahashi,T.;Arita,Y.\&Takahashi,M.(2000).PlasmaConcentrations of a Novel, Adipose-Specific Protein, Adiponectin, in Type 2 Diabetic Patients. ArteriosclerThrombVascBiol.20 (6):1595-1599.

[20]. Yenicesu, M.; Yilmaz, M. ; Caglar, K. ;Sonmez,A. ; Eyileten, T. \&Kir, T.(2005).Adiponectin level is reduced and inversely correlated with the degree of proteinuria in type 2 diabetic patients. ClinNephrol. 64 (1): 12-19.

[21]. Yamauchi, T.; Kamon, J.;Waki,H. ;Terauchi, Y.; Kubota, N.; Hara, K.\& Mori, Y.(2001).The fat-derived hormone adiponectin reverses insulin resistance associated with both lip atrophy and obesity. Nature Medicine .7(8):941-946.

[22]. Marshall, D.;Johnell, O.\& Wedel, H.(1996). Meta-analysis of how well measures of bone mineral density predict occurrence of osteoporotic fractures. BMJ.312 (7041):1254-1259.

[23]. Irzal,H.;Blazenka,M.;Vesna,C.;Deiti,P.andDragica,B.;(2008).Increased bone mineral density in postmenopausal women with type 2 diabetes mellitus. Accepted for publication January.28 (2): 102-104

[24]. Wakasugi,M.;Wakao,R.;Tawata,M.;Gan,N.;Koizumi,K.andOnaya,T.(1993).Bone mineral density measured by dual energy X-ray Absorptiometry in patients with non-insulin-dependent diabetes mellitus. Bone.14(1): 29-33.

[25]. Fulzele, K.; Riddle, RC.;DiGirolamo, DJ.; Cao, X.; Wan, C.; Chen, D.;Faugere, MC.; Aja ,S.Hussain, MA.;Bruning,JC.\& Clemens,TL. (2010). Insulin receptor signaling in osteoblasts regulates postnatal bone acquisition and body composition. Cell .142(2):309-319. 